\title{
Evaluation of the different genotype of Bitter Gourd in the Republic of Moldova
}

\author{
P. Iliev ${ }^{1}$, I. Ilieva ${ }^{1}$ and C. Staci ${ }^{1}$ \\ 1 Scientific and Practical Institute of Horticulture and Food Technologies, Chisinau, \\ Republic of Moldova
}

*Corresponding author email: petru.iliev27@gmail.com

\begin{abstract}
Bitter gourd ranks first among cucurbits and has great demand in international market, but not to spread in the Republic of Moldova despite this a due attention has not been given towards a need-based crop improvement. There is a prime need for Bitter gourd to evaluate cultivars suited to specific agro-ecological conditions. Three different genotypes of bitter gourd (Momordica charantia L.) were evaluated concerning yield and yield contributing traits. All genotypes showed relevant results and can be cultivated in the Republic of Moldova climate conditions. The best results were obtained on Indian and local genotypes of bitter gourd.
\end{abstract}

Keywords: biological characteristics, productivity, ecological condition, fruit number.

\section{INTRODUCTION}

Bitter melon-also known as bitter gourd or Momordica charantia is a tropical vine that belongs to the gourd family and is closely related to zucchini, squash, pumpkin, and cucumber.

Bitter melon is a fruit in the gourd family with a unique appearance and flavor. It's cultivated around the world for its edible fruit, which is considered a staple in many types of Asian cuisine.

It grows in several areas, including Asia, South America, the Caribbean, and East Africa. People have used bitter melon as a cultivar of medical conditions over time. Bitter gourd is an important vegetable domesticated in eastern India and southern China. It is cultivated commercially in Asia on $\approx 340,000$ ha annually (McCreight et al., 2013). It is also cultivated in smaller volumes in the southern United States and Australia (Northern Territory, Queensland, New South Wales, Victoria) using Asian cultivars. Asian cultivars are also grown in Ghana for fresh fruit export to European countries for their Asian communities. Its cultivation is gaining ground in Zambia, Congo, and Madagascar for local consumption and export. Nearly $60 \%$ of the bitter gourd production area is devoted to open-pollinated varieties (McCreight et al., 2013). Seed companies release numerous hybrid cultivars each year in Asia that are more consistent for quality and yield than open-pollinated cultivars. Four hundred thirty-four bitter gourd accessions that originated from more than 15 countries are housed in the genebank of AVRDC-The World Vegetable Center, Taiwan (McCreight et. al.,2013).

Bitter melon contains many nutrients that can be beneficial to your health. It's linked to lowering blood sugar, which some studies suggest means it can aid in diabetes treatment. It's not only rich in several important nutrients but also linked to numerous health benefits, including improved blood sugar control and cholesterol levels (Amirthaveni,et.al., 2018). 
Benefits of bitter melon and its extract. Bitter melon is a great source of several key nutrients. One cup (94 grams) of raw bitter melon provides: calories - 20, carbs - 4 g, fiber $2 \mathrm{~g}$, vitamin C - 93\% of the Reference Daily Intake (RDI), vitamin A - 44\% of the RDI, folate $17 \%$ of the RDI, potassium - $8 \%$ of the RDI, zinc - $5 \%$ of the RDI, iron - $4 \%$ of the RDI (Dhillon et. al., 2017).

Bitter gourd abounds in nutrients such as beta-carotene, vitamin C, folic acid, magnesium, phosphorus, and potassium (Yuwai et al., 1991). Recently the species has been considered as one of five crops, along with scuba rice, mung beans, disease-resistant bananas, and drought-hardy maize that have the potential to save the world (Rose, 2012).

Melons moved from India to central Asia, China, the Middle East, and Europe. The timeline for movement of melons to these areas is unknown, but a recent study of ancient manuscripts, the Hebrew Bible, and images from antiquity document the culture and uses of non-sweet melons in the Chate and Flexuosus groups as early as 1350 B.C. (Janick et al., 2007). Literature from Roman and medieval periods revealed that sweet melons were known in central Asia in the mid-9th century, Khorasan (Turkmenistan, Uzbekistan Afghanistan, Tajikistan, and northeastern Iran) and Persia by the mid-10th century, and in Andalusia (Spain) by the mid-11th century (Paris et al., 2012). These areas still to this day have a wealth of genetically diverse melon germplasm (Anon, 2008; Escribano et al., 2012; Esquinas-Alcazar, 1981; Mavlyanova et al., 2005a; McCreight et al., 2010).

Bitter melon is considered-complementary or alternative medicine. Therefore, the use of bitter melon isn't approved by the Food and Drug Administration (FDA) for the treatment of diabetes or any other medical condition. Bitter melon can be enjoyed raw or cooked in various recipes, it can be pan-fried, steamed, baked, or even hollowed out and stuffed with your choice of fillings. Chinese cooking, Bitter Melon is usually stir fried with pork, used in soups and consumed as a tea. Northern Indian Bitter Melon can be stuffed with spices and prepared by cooking in oil. It is prepared or served with yogurt to offset the bitterness. Southern India, Bitter Melon is mixed with coconut and stir-fried with various spices. Caribbean, Bitter Melon is sautéed with onion, garlic until crisp. The objective of us was to evaluate horticultural traits (fruit weight, fruit number/plant and fruit yield) of three bitter gourd genotypes in climatic and soil conditions in the Republic of Moldova.

\section{MATERIALS AND METHOD}

The experiment was conducted in the IP ISPHTA (Public Institution Scientific and Research Institute of Horticulture and Food Technologies).

A study was conducted with three different genotypes of bitter gourd one local, ('Genotype $\mathrm{A}^{\prime}$ ) one from China ('Genotype B'), and one of Indian origin ('Genotype C'). The experimental trial was arranged in a randomized complete block design (RCBD) with 4 replications. In each replication, genotypes were represented by 2 rows and each row contains 10 plants with row to row spacing $1,2 \mathrm{~m}$ and plant-plant spacing of $40 \mathrm{~cm}$. To ensure good germination seeds were sown in a greenhouse in the second decay of March in small plastic pots. Planting was done in the second decay of May with-seedlings produced in a greenhouse. Plant fertigation was done with mineral chemicals $\left(\mathrm{N}_{60}, \mathrm{P}_{60}, \mathrm{~K}_{60}\right)$ on planting into the furrow. Water supply was done by-drip irrigation, keeping the soil humidity at the level of $70-75 \%$ of soil capacity. In our study were analyzed both the technological and production characteristics, as well as the shape and color of the fruits. Productivity indicators were statistically analyzed with ANOVA of Experimental Data. 


\section{RESULT AND DISCUSSION}

Assessing the impact of technologies on yield and profitability of cultivation is an essential step before dissemination of the technologies for wider adaptation.

Bitter gourd has a slender hairy stem with numerous branches and dense foliage, develops small, yellow flowers both male and female, on the same plant. The fruits are green usually oblong an irregular surface with warts and 8-10 vertical ridges. When ripe, the fruits turn yellowish-orange in color. Plant in the condition of the Republic of Moldova plant grows up to $3,5-4,0 \mathrm{~m}$.

Bitter gourd develops many side branches that are not productive. To improve yield, remove lateral branches until the runner reaches the top of the trellis. Removal of lateral branches in the first nodes has a positive effect on total yield. Without pruning, most of the female flowers occur between the $10^{\text {th }}$ and $40^{\text {th }}$ nodes or at a height of $0.5-2.0 \mathrm{~m}$.

Bitter gourd yield can vary depending on cultivar and crop management. Average marketable yields are around 8-10 t/ha. In some areas, the yield rises till 20-30 t/ha. But there are producers which can get about 40 t/ha (Dhillon et.al., 2016)

There are two cultivars of bitter gourd. The large kind is long, oblong, and pale green. The other kind is small, a little oval, and dark green. Both types are bitter. The immature fruits and tender vine tips are used in a cultivar of culinary preparations. The fruits and shoots are soaked in saltwater to remove some of their bitterness and then boiled, fried, or pickled (Thakur et.al, 2018).

Mature fruits are ready to be picked within $2.0-2.5$ months from planting and they will be light green and juicy with white flesh but bitter. Pick the fruits every 2-3 days when they are still at the tender stage. Regular picking is important as fruits will become bitterer as they mature and it can also hamper the growth of new fruits. Young and tender fruits are picked on every alternate day and are supplied in the market. The harvested fruits should be kept under shade in a cool place. The immature fruits and tender vine tips are used in a cultivar of culinary preparations. The fruits and shoots are soaked in saltwater to remove some of their bitterness and then boiled, fried, or pickled. Unfortunately for the moment most farmers and consumers treat the biter gourd as an exotic plant and use it for eating only the red mass of the flash which covered seeds. This flesh has a sweet lovely taste.

Table 1. Reproductive characters of bitter gourd genotypes (2019 - 2020)

\begin{tabular}{|l|c|c|c|c|c|c|}
\hline Genotype & $\begin{array}{c}\text { Node no. of } \\
\text { first male } \\
\text { flower }\end{array}$ & $\begin{array}{c}\text { Node no. of } \\
\text { first female } \\
\text { flower }\end{array}$ & $\begin{array}{c}\text { Days to } \\
\text { first male } \\
\text { flower }\end{array}$ & $\begin{array}{c}\text { Days to } \\
\text { first female } \\
\text { flower }\end{array}$ & $\begin{array}{c}\text { Vine } \\
\text { length, } \\
\text { (cm) }\end{array}$ & $\begin{array}{c}\text { Inter nodal } \\
\text { length, (cm) }\end{array}$ \\
\hline 'Genotype A' & 10.4 & 12.3 & 21.1 & 22.0 & 3.7 & 11.2 \\
\hline 'Genotype B' & 13.2 & 17,3 & 25.5 & 27.4 & 4.5 & 10.9 \\
\hline 'Genotype C' & 12.5 & 18,1 & 22.3 & 21.6 & 4.2 & 9.7 \\
\hline
\end{tabular}

Bitter gourd requires close attention at harvest time. The fruits develop rapidly and must be harvested frequently to keep them from becoming too large or too bitter. Normally it takes 15-20 days after fruit set or 90 days from planting for fruit to reach marketable age, however, bitter gourd can be harvested at earlier stages depending on the purpose for which it will be used. Fruit should be light green, thick, and juicy and the seeds should be soft and white. Harvest every 2-3 days using a pair of scissors or a sharp knife to cut the fruit stalk. If a fruit remains too long on the vine, it will turn spongy, sour yellow, or orange and split open.

Genotype, due to their biological particularity, had different responses on plant length, days to the first male and female flowers, numbers of nodes, fruits, etc. (Akram et. al., 2021). 
The Southeast Asian type of bitter gourds due to biological peculiarities form late the male and female flowers, have a dark green color of the fruits in technical stage and higher vine and fruits length (Table 1).

The number of days to male and female flower induction help in the development of early or late fruit yield which is important for the grower to know how to organize and expand a supply to the market.

Table 2. Technological and production characteristics of bitter gourd at the studied genotypes, in the condition of the Republic of Moldova (2019 - 2020).

\begin{tabular}{|l|c|c|c|c|c|c|}
\hline Genotype & $\begin{array}{c}\text { Fruit } \\
\text { length, cm }\end{array}$ & $\begin{array}{c}\text { Fruit } \\
\text { diameter, cm }\end{array}$ & $\begin{array}{c}\text { No. } \\
\text { fruit/plant }\end{array}$ & $\begin{array}{c}\text { Average fruit } \\
\text { weight (g) }\end{array}$ & $\begin{array}{c}\text { Fruit yield } \\
\text { (kg/plant) }\end{array}$ & $\begin{array}{c}\text { Fruit yield } \\
(\mathrm{Mt} \cdot \mathrm{h})\end{array}$ \\
\hline 'Genotype A' & $11.4 \pm 0.7$ & $4.5 \pm 0.8$ & $14.4 \pm 1.9$ & $195.3 \pm 12.1$ & $1.9 \pm 0.15$ & $15.4 \pm 0.6$ \\
\hline 'Genotype B' & $14.1 \pm 0.9$ & $3.9 \pm 0.6$ & $9.3 \pm 2.0$ & $173.2 \pm 9.1$ & $1.6 \pm 0.12$ & $12.1 \pm 0.25$ \\
\hline 'Genotype C' & $17.8 \pm 0.6$ & $4.1 \pm 0.4$ & $12.7 \pm 1.3$ & $275.3 \pm 13.7$ & $2.1 \pm 0.17$ & $17.3 \pm 0.9$ \\
\hline LSD & 1.4 & 1.1 & 2.1 & 18.2 & 0.2 & 1.6 \\
\hline
\end{tabular}

The results look like that 'Genotype $\mathrm{C}^{\prime}$ had the longest fruit $(17.8 \mathrm{~cm})$ which is longer with $6.4 \mathrm{~cm}$, than 'Genotype $\mathrm{A}$ ' and $3.7 \mathrm{~cm}$ in comparison with genotype B (Table 2). The highest fruit diameter was observed in 'Genotype A' $(4.5 \mathrm{~cm})$, and the lowest $(3.9 \mathrm{~cm})$ belonged to 'Genotype B'. Weight and yield per plant also depend on genotype. The fruit number per plant depends on the plant's genetics, growth conditions, and crop management practices, as reported by several studies (Ribersor and Decker-Walters, 1997; Singh and Kandasamy, 2021; Yaldız, ,2015; Dudhat and Patel, 2020). The diameter of the fruit is a very important qualitative element, which in addition to hereditary influences is strongly influenced by environmental and culture factors (Akram et. al., 2021). Yield is a complex attribute that is strongly influenced by environmental factors (Amizi, 2008). The yield potential of different cultivars of a single plant species varies from one environment to another, and cultivars do not show the same yield potential in different environments (Gupa et. al., 2015). The best results from the two years of experiments, on fruit production per plant, were obtained in the Indian genotype ('Genotipe C'), followed by the local genotype ('Genotipe A'). The number of fruits per plant ranged from 9.3 ('Genotype B') to 14.4 ('Genotype A').

Table 3. Fruits index characteristics

\begin{tabular}{|c|c|c|c|c|c|}
\hline Genotype & Shape index & Shape form & $\begin{array}{c}\text { Unripe fruits } \\
\text { color }\end{array}$ & Skin pattern \\
\hline 'Genotype A' & 2.53 & spindle & white & \multicolumn{2}{|c|}{ spiny } \\
\hline 'Genotype B' & 3.61 & elongated & green & spiny \\
\hline 'Genotype C' & \multicolumn{2}{|c|}{4.3} & long & dark green & spiny \\
\hline
\end{tabular}

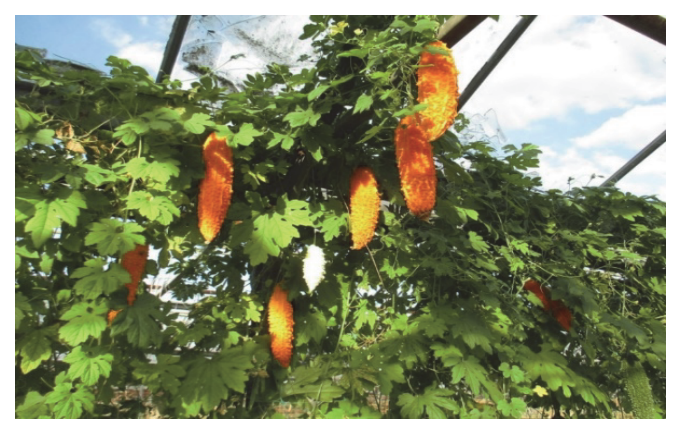

Figure 1. Bitter gourd plant with mature fruits Indian genotype. 
Consumers prefer bitter gourd fruit at a physiologically immature or unripe stage and it is correlated with fresh bright appearance of fruits and immature creamy white seedcoat. Consumers display a wide range of preference for fruit color, shape, skin pattern and size, which varies between and within countries (McCreight, 2013). Fruit color ranges from white or cream to light green to dark green and the various shapes include cylindrical, elliptical, spindle, and conical. Fruits of different varieties may have regular or irregular longitudinal ridges and warty skin (McCreight, 2013).

The genotypes differ from each other by fruit shape, form, and color (Table 3). Local 'Genotype $A^{\prime}$ had an index shape to 2.53, white unripe fruits color, and spindle form, 'Genotype B' index shape is 3.61, fruits elongated of green color. The highest index of shape (4.31) belongs to 'Genotype C'. This genotype is characterized by long form of dark green fruits color.

\section{CONCLUSIONS}

This study, which was conducted for the first time in the Republic of Moldova, states that there is potential for economic production of this plant in climatic conditions of the Republic of Moldova, the highest production being recorded in 'Genotype C'. All genotypes studied obtained good results in terms of technological characteristics and fruit production. At the same time, the right choice of variety has significant importance. Evaluated genotypes of different origins showed different results by several formed fruits, their index shape form, and by yield per plant. In the future, additional studies are needed, for several years, both in terms of quantitative, qualitative and chemical indicators of the bitter gourd plant.

\section{REFERENCES}

1. Anon A. (2008). Türkmen gawunlary atlas, 3-nji nesir (Turkmen melons. Atlas, 3rd ed.). Food Industry Association of Turkmenistan, Ashgabat

2. Akram V.,Majid A., Abdolkarim K., Ramaraj S. ,Sang Un Park, Akifumi S.,Takashi M. and Yoshiharu F. (2021). Evaluation of growth, yield, and biochemical Attributes of Bitter Gourd (Momordica charantia L.) Cultivars under Karaj Conditions in Iran. Plants (2021), 10, (7), 1370.

3. Amirthaveni, M., Premakumari, S., Gomathi, K. and Yang, R.Y. (2017). Hypoglycemic Effect of Bitter Gourd (Momordica charantia L.) among pre diabetics in India: A Randomized Placebo Controlled Cross Over Study. The Indian Journal of Nutrition and Dietetics, 55(1):44-63

4. Azizi, M. (2008). Change in content and chemical composition of Hypericum perforatum L. oil at three harvest time. J Herbs Spices Med. Plants (2008), 13, 79-85.

5. Behera T.K., Singh A.K., and Staub J.E, (2008). Comparative analysis of genetic diversity in Indian bitter gourd (Momordica charantia L.) using RAPD and ISSR markers for developing crop improvement strategies. Scientia Horticulturae. (2008), 115:209-217.

6. Dhillon P. S, Chung-Cheng L. Sun Z, Hanson P. M., Ledesma D.R, Habicht S. D. and Yang R.Y (2017). Varietal and harvesting stage variation in the content of carotenoids. ascorbic acid and tocopherols in the fruit of bitter gourd (Momordica charantia L.). Plant Genetic Resources. -Charact. Util. 15. 248-259. Volume 15, Issue 9, pp. 248-259

7. Dudhat, M. and Patel, K. Evaluation of integrated nutrient management on the performance of quality and yield attributes of hybrid bitter gourd VNR 22 (Momordica charantia L.). J. Pharmacogn. Phytochem. (2020), 9, 1643-1645

8. Escribano, S., Lázaro, A., Cuevas, H.E., Staub, J.E., López-Sesé, A.I. and Staub, J.E. (2012). Spanish melons (Cucumis melo L.) of the Madrid provenance: A unique germplasm reservoir Genet. Resources Crop Evol. 59359373

9. Esquinas-Alcazar, J.T. (1981). Alloenzyme variation and relationships among Spanish land-races of Cucumis melo L Kulturpflanze, 29: 337-352

10. Gupta N., Bhardwaj M., Singh, S. and Sood, S. (2015). Correlation and path analysis of yield and yield components in some genetic stocks of bitter gourd (Momordica charantia L.). Sabrao J. Breed. Genet. (2015), 47: 475-481.

11. Islam MR., Hossain MS., Bhuiyan MSR., Hasan GN. and Syed A. (2010). Multivariate analysis of bitter gourd (Momordica charantia L.). Middle East Journal of Scientific Research. (2010); No.2, pp.86-90 5:89-90. 
12. Janick, J., Paris, H.S. and Parrish, D.C. (2007). The cucurbits of Mediterranean antiquity: Identification of taxa from ancient images and descriptions Ann. Bot. (Lond.) 100: 1441-1457.

13. Mavlyanova, R.F., Abdullaev, F.K., Khodjiev, P., Zaurov, D.E., Molnar, T.J., Goffreda, J.C., Orton, T.J. \& Funk, C.R. (2005b). Plant genetic resources and scientific activities of the Uzbek Research Institute of Plant Industry HortScience, 40: 10-14.

14. McCreight, J.D., Kokanova, E., Wehner, T.C. and Davis, A.R. (2010) Turkmenistan melon (Cucumis melo), and watermelon (Citrullus lanatus) germplasm expedition 2008. Cucurbitaceae (2010) Proc., 14-18 Nov. 2010, Charleston, SC

15. McCreight J.D., Staub J. E., Wehner T.C., and. Dhillon P.S (2013). Gone Global: Familiar and Exotic Cucurbits Have Asian Origins. Hortscience 48:1078-1089.

16. Ngullie R. and Biswas P.K. (2015). Evaluation of bitter gourd genotypes for yield attributes in Mokokchung district. Nagaland. International Journal of Farm Sciences. (2015); 5 (3):56-59.

17. Paris, H.S., Amar, Z. and Lev, E. (2012). Medieval emergence of sweet melons, Cucumis melo (Cucurbitaceae) Ann. Bot. (Lond.), 110: 23-33.

18. Robinson, R. and Decker-Walters, D. (1997). Cucurbits in crop production science in Horticultures Series; CABI: (1997). USA,

19. Rose, E. (2012). Five foods that will save the world Reader's Digest, U.K. Edition February, pp: 82-88.

20. Singh, W.J. and Kandasamy, R. (2020) Genetic Diversity in Bitter Gourd (Momordica Charantia L.) Under Coastal Ecosystems. Plant Arch 20:1063-1066.

21. Thakur V., Kumar S., Tiwari R. and Chormule S.R. (2018). Yield and yield contributing traits of bitter gourd (Momordica charantia L.) genotypes. Journal of Pharmacognosy and Phytochemistry (2018); $7(3)$ : 844846

22. Walters, T.W. and Decker-Walters, D.S. (1988). Balsampear (Momordica charantia, Cucurbitaceae) Econ. Bot. 42: 286-288.

23. Yadagiri J., Gupta N.K. Tembhire D. and Verma S. (2017). Genetic variability heritability and morphological characterization in Bbitter gourd (Momordica charantia L.). International Journal of Pure and Applied Bioscience. (2017); 5(4):1322-1327.

24.Yaldız, G.; Sekeroglu, N.; Kulak and Demirkol, G. (2015). Antimicrobial activity and agricultural properties of bitter melon (Momordica charantia L.) grown in northern parts of Turkey: A case study for adaptation. Nat. Prod. Res. (2015), 29: 543-545.

25. Yuwai, K.E., Rao, K.S., Kaluwin, C., Jones, P.G. and Rivett, D.E. (1991). Chemical composition of Momordica charantia L. fruits J. Agr. Food Chem. 39: 1762-1763 